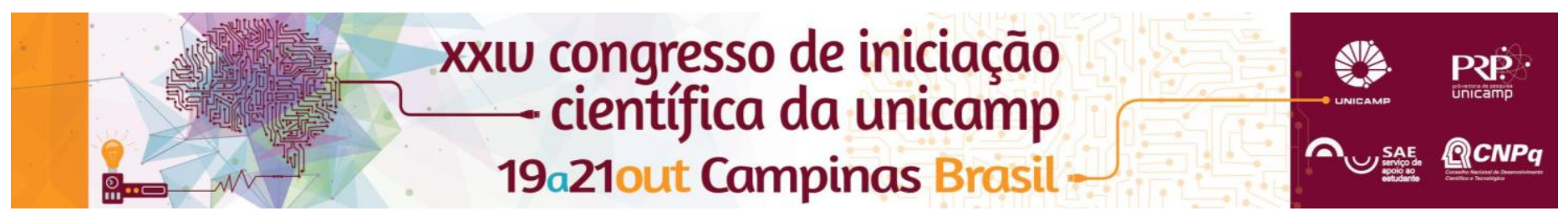

\title{
Vivendo e aprendendo: Percepção e olhares de alunos do ensino médio na adaptação de materiais para pessoas com deficiência visual.
}

\section{Audria K. I. Almeida*, Maria Elisabete Rodrigues Freire Gasparetto.}

\section{Resumo}

Este projeto teve como objetivo geral, propiciar que alunos do ensino médio desenvolvessem a adaptação de livros e jogos para o uso de crianças, adolescentes e adultos com deficiência visual. Foram realizadas a adaptação de quatro livros infantis: "A Baleia", "O Barco", "Confusão no Jardim" e "Um dia de abelha" e de quatro jogos: "Dominó", "Jogo da Velha", "Dama" e "Trilha" (de tabuleiro), visando a acessiblidade à pessoa com deficiência visual. Os materiais adaptados foram utilizados e analisados por pessoas com deficiência visual.

Palavras-chave: Deficiência Visual, Acessibilidade, Materiais Adaptados.

\section{Introdução}

A deficiência visual inclui a baixa visão e a cegueira e o desempenho visual dessas pessoas pode ser melhorado por meio do uso de Recursos de Tecnologia Assistiva, que propiciam acessibilidade aos materiais de uso cotidiano'. Este projeto teve como objetivo, propiciar que alunos do ensino médio desenvolvessem a adaptação de livros e jogos para o uso de crianças, adolescentes e adultos com deficiência visual.

\section{Resultados e Discussão}

Para realizar a acessibilidade, os alunos tiveram que deter conhecimentos acerca da deficiência visual e da reabilitação dessas pessoas. Para esse processo utilizouse de literatura especializada, legislação nacional, filmes e simuladores de deficiência visual.

Foram realizadas a adaptação de quatro livros infantis: "A Baleia"2", "O Barco ${ }^{3 ",}$ "Confusão no Jardim ${ }^{4 "}$ e "Um dia de abelha ${ }^{5}$ ", que foram utilizados e avaliados por crianças com baixa visão. Os jogos: "Dominó", "Jogo da Velha", "Dama" e "Trilha" foram avaliados por adultos cegos e com baixa visão. Em relação aos livros, todas as crianças gostaram muito das adaptações e conseguiram ter acesso ao conteúdo dos livros. Em relação ao "Jogo da Velha" e da "Trilha", as pessoas cegas e com baixa visão relataram que eles estavam acessíveis. Em relação ao "Dominó", as pessoas com baixa visão disseram que algumas cores estavam difíceis de serem identificadas e sugeriram a utilização de cores mais contrastantes, visando a melhor iidentificação do jogo. Em relação a "Dama", após algumas rodadas do jogo, partes do tabuleiro foram se descolando. Por isso, esse jogo teve que ser refeito.

A acessibilidade não ficou restrita em materiais mas, deu espaço à comunicabilidade virtual, por meio de um blog que divulgou o presente projeto, mostrando os caminhos trilhados pelos alunos do ensino médio na elaboração dos materiais adaptados.

\section{Conclusões}

Entre tantas adaptações, é possível concluir que, o objetivo principal do projeto foi efetivado, por propiciar a alunos do ensino médio, competência e conhecimentos específicos acerca da deficiência visual, o que proporcionou a acessibilidade de livros e jogos para o uso e melhor conforto de pessoas com deficiência visual.

Figura 1. Adaptação do livro "A Baleia"

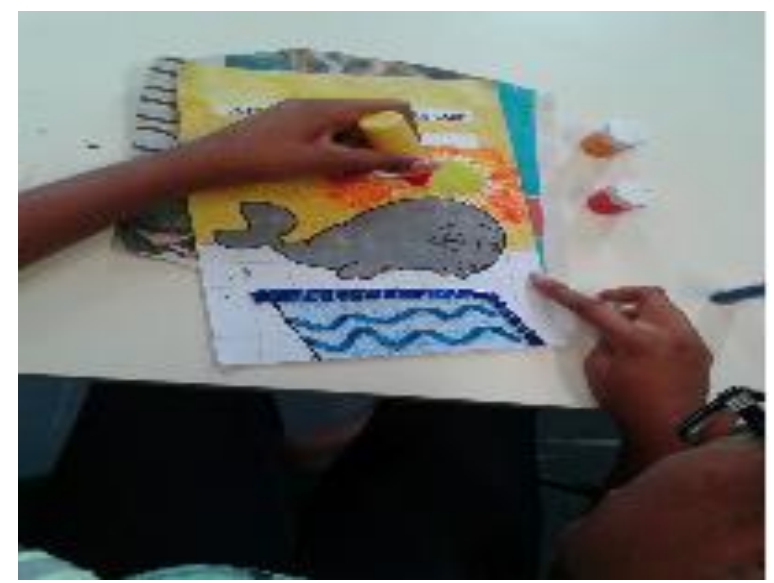

\section{Agradecimentos}

Agradeço ao Programa Institucional de Bolsas de Iniciação Científica do Ensino Médio (PIBIC EM) e a um dos órgãos que financia o projeto: $\mathrm{CNPq}$, pela grande oportunidade cedida a alunos do ensino médio. Agradeço também as alunas do ensino médio Andressa Timoteo Pereira e Viviane de Jesus Silva, por terem participado do projeto e da adaptação de alguns dos livros e jogos, mas que se desligaram do projeto bruscamente por causas pessoais.

\section{Referências Bibliográficas}

1 Carvalho, K. M. M. de. et al. Visão Subnormal. 2. ed.

Campinas: Unicamp, 1994.

2.Fedman, C. A Baleia. São Paulo: FTD,1986

3. França, M; França, E.O Barco. São Paulo: Ática, 1995.

4. Verdolin Filho, F. Confusão no Jardim. São Paulo: FTD, 2006.

5. Pinto, F. R. Um dia de abelha. Delo Horizonte: FAPI. 